\title{
ENSAIO SOBRE O VALOR SOLIDARIEDADE: PROPOSTA TEÓRICO-HERMENÊUTICA PARA SUPERAÇÃO DO PARADIGMA ECONÔMICO NEOLIBERAL
}

ESSAY ON SOLIDARITY VALUE: A THEORETICAL-HERMENEUTICAL PROPOSAL TO OVERCOME THE NEOLIBERAL ECONOMIC PARADIGM

\section{ENSAYO SOBRE EL VALOR SOLIDARIDAD: PROPUESTA TEÓRICA HERMENÉUTICA PARA LA SUPERACIÓN DEL PARADIGMA ECONÓMICO NEOLIBERAL}

\section{Jailton Macena de Araújo'}

Licença CC BY:

Artigo distribuído sob os termos Creative Commons, permite uso e distribuição irrestrita em qualquer meio desde que $o$ autor credite a fonte original.

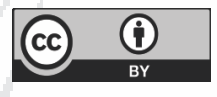

\begin{abstract}
Resumo: No contexto brasileiro atual, a crise econômica e social se coloca como ponto central das discussões políticas. Nesta perspectiva, os direitos sociais devem ser implementados sob a conformação do valor social do trabalho, de modo a promover a materialidade axiológica assegurada no texto constitucional, a qual tem como objetivo a construção de uma sociedade livre, justa e solidária. Desta forma, é a partir da teoria da solidariedade que é possível respaldar, nas concepções pós-positivistas do direito (assentadas na ideologia liberal), uma discricionariedade que reorienta as demandas e as decisões do poder público para o núcleo constitucional que é evidenciado pelos direitos sociais. Assim, se coloca como problema a ser enfrentado no presente trabalho: é possível, nos termos dos valores abrigados na Constituição Federal de 1988, que prevê o equilíbrio socioeconômico democrático, promover a superação do paradigma econômico neoliberal, em busca da efetivação da solidariedade e da justiça social? Reconhecese que as discussões para se responder à pergunta são bem amplas e contraditórias, mas não se pode descurar que, embora haja uma pluralidade de alternativas, o núcleo comum, definido também pelo texto constitucional, é a racionalidade solidária, que a subjaz, estabelecendo-se como proposta teórico-hermenêutica os valores sociais do trabalho, da solidariedade e da justiça social como mecanismo de efetivação de uma democracia social e solidária. Para tanto, parte-se da proposta teórico-metodológica hipotético-dedutiva, na qual se reconhece a força normativa da constituição e o seu protagonismo na promoção do bem-estar preconizado no seu texto. Reconhece-se ainda que, apesar das adversidades socioeconômicas impostas pela realidade de crise do capital, apenas a racionalidade solidária será capaz de promover o equilíbrio necessário à manutenção da relação capital $x$ trabalho.
\end{abstract}

Doutor em Ciências Jurídicas pela Universidade Federal da Paraíba. Professor Permanente do Programa de Pós-Graduação em Ciências Jurídicas da UFPB. Docente vinculado ao Departamento de Direito Processual e Prática Jurídica do CCJ/UFPB. Editor Gerente da Prim@ Facie (revista do PPGCJ/UFPB). João Pessoa, Paraíba, Brasil. E-mail: jailtonma@gmail.com. 
Palavras-chave: Racionalidade solidária; Tolerância; Superação do economicismo; Matriz ideológica constitucional; Cidadania.

Abstract: In the current Brazilian context, the economic and social crisis is at the heart of political discussions. From this perspective, social rights should be implemented under the conformation of the social value of labor, in order to promote the axiological materiality that is guaranteed in the constitutional text, which aims to build a free, fair and supportive society. Thus, through the theory of solidarity, it is possible to support, in the post-positivist conceptions of law (based on the liberal ideology), a discretionarity that reorients the demands and decisions of the public power to the constitutional nucleus that is evidenced by social rights. Thus, the problem to be faced in the present work is as follows: it is possible, in terms of the values enshrined in the Federal Constitution of 1988, which provides for socioeconomic democratic balance, to promote the overcoming of the neoliberal economic paradigm, in search of effective solidarity and social justice? It is recognized that the discussions requested to answer the question are quite broad and contradictory, but it cannot be overlooked that although there is a plurality of alternatives, the common nucleus, also defined by the constitutional text, is the solidarity rationality that underlies it and establishes, as a theoretical-hermeneutic proposal, the social values of work, solidarity and social justice as a mechanism for implementing a social and solidarity democracy. It begins with a hypothetical-deductive theoretical-methodological proposal, in which the regulatory force of the constitution, and its protagonism in the promotion of the well-being advocated in its text, are recognized. It is also recognized that despite the socioeconomic adversities imposed by the reality of capital crisis, only solidary rationality will be able to promote the balance necessary to maintain the capitallabor relation.

Keywords: Solidary rationality; Tolerance; Overcoming economism; Constitutional ideological matrix; Citizenship.

Resumen: En el contexto brasileño actual, la crisis económica y social se coloca como punto central de las discusiones políticas. En esta perspectiva, los derechos sociales deben ser implementados sobre la conformación del valor social del trabajo, para promover la materialidad axiológica asegurada en el texto constitucional, la cual tiene como objetivo la construcción de una sociedad libre, justa y solidaria. De esta forma, es a partir de la teoría de la solidaridad que es posible respaldar, en las concepciones pos-positivistas del derecho (basadas en la ideología liberal), una discrecionalidad que reorienta las demandas y las decisiones del poder público para el núcleo constitucional que es evidenciado por los derechos sociales. Así, se coloca como problema a ser enfrentado en el presente trabajo: ¿es posible, en los términos de los valores consagrados en la Constitución Federal de 1988, que prevé el equilibrio socioeconómico democrático, promover la superación del paradigma económico neoliberal, en búsqueda de la efectiva solidaridad y de la justicia social? Se reconoce que las discusiones para responder a la pergunta son bien amplias y contradictorias, pero no se puede omitir que, aunque haya una pluralidad de alternativas, el núcleo común, definido también por el texto constitucional, es la racionalidad solidaria, que lo sustenta, estableciendo como propuesta teórica hermenéutica los valores sociales del trabajo, de la solidaridad y de la justicia social como mecanismo efectivo de una democracia social y solidaria. Para tanto, se parte de la propuesta teórica metodológica hipotética deductiva, en la cual se reconoce la fuerza normativa de la constitución y su protagonismo en la promoción del bienestar preconizado en el texto. Se reconoce que, a pesar de las adversidades socioeconómicas impuestas por la realidad de la crisis del capital, apenas la racionalidad solidaria será capaz de promover el equilibrio necesario para el funcionamiento de la relación capital $x$ trabajo.

Palabras clave: Racionalidad solidaria; Tolerancia; Superación del economicismo; Matriz ideológica constitucional; Ciudadanía. 


\section{INTRODUÇÃO}

No contexto brasileiro atual, em que a crise econômica e social se coloca como ponto central das discussões políticas, cada vez mais, ganha importância a chamada questão social, que tem como pontos primordiais o trabalho, a assistência social, os programas e as ações estatais de combate à miséria e a realização dos direitos sociais, cada dia mais deixados em segundo plano.

Nesta perspectiva, para estes direitos atinentes à dignidade humana dos cidadãos, devese reconhecer que o trabalho é o mecanismo primordial de realização pessoal e de garantia de participação dos sujeitos nos rumos do Estado. Assim, programas e ações devem ser implementados sob a conformação do valor social do trabalho, de modo a promover a materialidade axiológica assegurada no texto constitucional, a qual tem como objetivo a construção de uma sociedade livre, justa e solidária.

A opção pela solidariedade como valor primordial para o direcionamento dos objetivos brasileiros, definidos na Constituição Federal de 1988, confere aos valores justiça social, valorização do trabalho e dignidade humana a condição de parâmetro por meio dos quais devem ser examinadas as regras e as ações do poder público. Sendo assim, para que se mantenha a coerência da ordem jurídica, é imperioso que a organicidade do ordenamento jurídico seja estabelecida e preservada, de modo que os valores albergados na norma constitucional sejam postos em prática.

Desta forma, é a partir da teoria da solidariedade que é possível respaldar, nas concepções pós-positivistas do direito (assentadas na ideologia liberal), uma discricionariedade que reorienta as demandas e as decisões do poder público para o núcleo constitucional que é evidenciado pelos direitos sociais. Assim, se coloca como problema a ser enfrentado no presente trabalho: é possível, nos termos dos valores abrigados na Constituição Federal de 1988, que prevê o equilíbrio socioeconômico democrático, promover a superação do paradigma econômico neoliberal, em busca da efetivação da solidariedade e da justiça social?

Reconhece-se que as discussões para se responder o questionamento são bem amplas e contraditórias, mas não se pode descurar que, embora haja uma pluralidade de alternativas, o núcleo comum, definido também pelo texto constitucional, é a racionalidade solidária, que a subjaz, a qual estabelece como proposta teórico-hermenêutica os valores sociais do trabalho, da solidariedade e da justiça social como mecanismo de efetivação de uma democracia social e solidária. Para tanto, parte-se da proposta teórico-metodológica hipotético-dedutiva, na qual se reconhecem a força normativa da constituição e o seu protagonismo na promoção do bem-estar preconizado no seu texto. Reconhece-se ainda que, apesar das adversidades socioeconômicas impostas pela realidade 
de crise do capital, apenas a racionalidade solidária será capaz de promover o equilíbrio necessário à manutenção da relação capital $x$ trabalho.

\section{RACIONALIDADE E PODER ECONÔMICO NA IDEOLOGIA DE EFETIVAÇÃO DA CONSTITUIÇÃO FEDERAL BRASILEIRA DE 1988: LIMITES E DESAFIOS}

A Constituição Federal de 1988, ao apresentar a estrutura econômica que deve ser seguida pelo Estado brasileiro, aponta alguns elementos como essenciais à atuação estatal. Assim é estabelecido o estatuto jurídico que orienta a atuação estatal na Ordem Econômica (artigo 170 e seguintes), pautada na regulamentação das relações econômicas entre o Estado, o mercado e a sociedade.

Ao Estado cabe o papel de agente normativo e regulador da atividade econômica, exercendo, na forma da lei, as funções de fiscalização, o incentivo e o planejamento, sendo este determinante para o setor público e indicativo para o setor privado. Para tanto, a lei estabelecerá as diretrizes e as bases do planejamento do desenvolvimento nacional equilibrado, o qual incorporará e compatibilizará os planos nacionais e regionais de desenvolvimento.

O texto constitucional aponta ainda como determinante para a adequada conformação da ordem econômica brasileira a repressão ao abuso do poder econômico que vise à dominação dos mercados, à eliminação da concorrência e ao aumento arbitrário dos lucros. A aceitação desse postulado revela que o poder econômico é a grande ameaça ao equilíbrio das forças sociais. Desta maneira, o Estado deve sujeitar o poder econômico ao controle do abuso sob o parâmetro da garantia e da defesa dos direitos humanos.

Os direitos humanos apresentam-se, pois, como instrumento efetivo de proteção à pessoa humana e à sua dignidade e servem, assim, como parâmetro a ser seguido na imposição dos limites ao poder econômico, de modo a evitar o seu abuso. Assim sendo, a presença dos direitos humanos fundamentais em uma ordem jurídica aponta para adoção de um modelo de Estado que se pretende verdadeiramente democrático.

O reconhecimento do valor dos direitos humanos serve para definir as implicações normativas e estruturais na efetivação dos direitos de cidadania, que são acompanhados de critérios claros para sua realização. Reconhecer a normatividade dos direitos humanos é estabelecer também quais são os poderes constituídos e quais as suas atribuições e seus núcleos de competências, de modo a se impedirem ingerências e abusos. 
Definem-se e evidenciam-se o papel da impositividade das leis e o relevante papel da Constituição, além de reconhecer a fonte da atuação estatal pautada na legalidade da atuação da administração pública. Obviamente, determina-se também o respeito aos direitos e às liberdades fundamentais. É nesses termos que se admite que o Estado brasileiro, ao promulgar a sua Constituição de 1988, optou por um verdadeiro "Estado Democrático Solidário de Direito" como paradigma que vai muito além do Estado Liberal ou do Estado Social. Conforme ressaltado por Bolaños ${ }^{2}$, o Estado liberal prevê os direitos de liberdade ou de autonomia; já o Estado Social prevê os direitos de igualdade, sociais ou prestacionais como fundamento primordial de sua atuação. O aqui defendido "Estado Democrático Solidário de Direito" reúne essas duas perspectivas e se propõe ainda ao aperfeiçoamento dos mecanismos de participação política e de democracia, no sentido de promover, àqueles que não têm condições de inserção, a participação nos frutos do desenvolvimento.

O desenvolvimento, no Estado Mínimo ou Liberal, dissocia as esferas econômica e social levando à autodestruição da solidariedade, com a marginalização cada vez mais acentuada dos excluídos. Na realidade, é imperioso que a inserção social seja identificada como a principal alternativa de realização dos direitos sociais a partir da compreensão do ambiente de lutas e de conquistas que são fomentadas pelo trabalho. A criação dos elementos de proteção social acaba sendo fundada em atos seletivos oriundos das necessidades reais das pessoas que estão envolvidas nas relações socioeconômicas inseridas, portanto, no mercado laboral. A proteção social aos mais vulneráveis não é construída apenas de uma previsão formal do direito, mas decorre da consciência geral e racional dos poderes constituídos acerca das mazelas sociais que afligem mais fortemente a classe dos trabalhadores, que tem condições de viver do trabalho, mas é marginalizada. A racionalidade passa então a ser considerada o pressuposto inicial para a definição dos argumentos jurídicos que condicionam a atuação dos poderes constituídos, bem como determinam a importância e o grau de respeito aos direitos fundamentais dos mais pobres.

Consoante as reflexões de $\mathrm{Fiani}^{3}$, a adoção de uma racionalidade ajuda a entender teoricamente o processo de decisões políticas dos agentes sociais que interagem entre si, a partir da compreensão lógica da situação em que estão envolvidos. A racionalidade adotada como proposta teórica de estratégia ajuda a desenvolver a capacidade de explorar as possibilidades de desenvolvimento de ações, especialmente por parte do Estado. A racionalidade torna válida a pressuposição jurídica que determina o modo de agir estatal. Ocorre que, na exigência do capital, a condição racional que determina o agir social impede o exercício real e pleno da cidadania. Ser cidadão, nessas condições, é apenas uma condição jurídica que não emancipa nem beneficia em nada o ser humano.

3

BOLAÑOS, Liliana Ortiz. Los derechos fundamentales como limites ao poder y la fuerza normativa da constituicion. In: Derecho y sociedad: Revissta del centro de investigaciones sociojurídicas, vol. 1, n. 1, Bogotá: Faculdades de Ciencias Jurídicas y del Estado, maio 2008 , p. 22.
FIANI, Ronaldo. Teoria dos jogos: para cursos de administração e economia. 2. ed. rev. e atual. Rio de Janeiro: Elsevier, 2006, p. 9-10. 
A cidadania, vislumbrada ante mecanismos apartados da emancipação, é convertida em uma quimera, que acaba delimitando o agir político e social em um mecanismo para submeter as pessoas à sujeição. É o que faz (e tem feito) a ideia liberal clássica de que o mercado determina as melhores regras a partir da autorregulação e da regulamentação financeira.

A democracia, pautada numa racionalidade econômica e liberal já não se sustenta mais. Como bem critica DeJours ${ }^{4}$, a:

[...] adesão à causa economicista, que separa a adversidade da injustiça, não resultaria, como se costuma crer, da mera resignação ou da constatação de impotência diante de um processo que nos transcende, mas funciona também como uma defesa contra a consciência dolorosa da própria cumplicidade, da própria colaboração e da própria responsabilidade no agravamento da adversidade social.

Como se pode depreender, o predicado racional é introduzido numa acepção em que os sujeitos se dispõem a permanecer sob determinadas condições e dispostos a viver sob uma dada ordem, denominada racional, a qual orienta as relações exteriores no mundo.

A partir das reflexões de Habermas ${ }^{5}$, pode-se identificar que o liberalismo se assenta na condução individual da vida de cada cidadão, sem que haja qualquer interferência por parte do Estado. A esfera pública e a esfera privada, sob essa compreensão, adquirem um significado precípuo determinado pela interpretação que se dá à liberdade econômica.

Pode-se estabelecer que ninguém "pode ser livre à custa da liberdade de outro" e a realização de ações coletivas, de cunho público, em favor da liberdade econômica de uma minoria, não seria a forma de atuação mais "justa" para promover a liberdade. Ainda, neste sentido, Soares Júnior 6 , para quem:

A banalização do sofrimento humano, somado ao apego positivista que defende a neutralidade axiológica e o emprego da metodologia própria das ciências exatas para a resolução de questões sociais, fazem o operador do Direito, muitas vezes, um mero reprodutor da injustiça produzida por uma sociedade desigual.

É neste sentido que se renova a premissa de Georges Ripert", para quem "Quando o direito ignora a realidade, a realidade se vinga, ignorando o direito". Desde a época de Hobbes, as regras do direito privado se apoiam na liberdade dos contratos e na propriedade, o que conformou o desenvolvimento das demais searas do direito em torno de uma ideologia privada egoísta.

DEJOURS, Cristophie. A banalização da injustiça social. Rio de Janeiro: FGV, 1999, p. 12.

HABERMAS, Jürgen. Direito e democracia: entre facticidade e validade. vol. 1. Tradução de Flávio Beno Siebeneichler. Rio de Janeiro: Tempo Brasileiro, 1997, p. 123.

6 SOARES JÚNIOR, Jair. A influência do argumento econômico sobre o jurídico na aplicação do direito à assistência social. In: SERAU, Marco Aurélio et al. (Org.). Benefício assistencial: Lei n 8.742/93 - temas polêmicos, p. 32-42. São Paulo: LTr, 2015, p. 34. RIPERT, Georges. A Regra Moral nas Obrigações Civis. Campinas: Bookseller, 2000. 
Essa concepção egoística e econômica fundada na ética da acumulação de recursos era determinante para o ganho e a consolidação do modo de produção atual que foi denominado por Weber como o "espírito do capitalismo". É exatamente nesse sentido que Weber ${ }^{8}$ define a racionalidade econômica como um imenso cosmos, no qual o indivíduo nasce e é obrigado a viver diante de uma ordem inalterável de coisas. Para ele, a racionalidade econômica:

[...] força o indivíduo, na medida em que esse esteja envolvido no sistema de relações de mercado, a se conformar com as regras de comportamento capitalistas. O fabricante que se opuser a essas normas será inevitavelmente eliminado do cenário econômico, tanto quanto um trabalhador que não possa ou não queria se adaptar às regras, que será jogado na rua, sem emprego 9 .

Weber parte da distinção entre os aspectos materiais e formais do direito, discutindo a sua racionalização sob ambos os pontos de vista, atribuindo, inclusive, a cada uma das perspectivas, pesos diferentes para a consecução dos fins estatais. Nessa medida, é preciso que se estabeleça uma racionalização, tanto dos caminhos do direito como da base do direito, que embora estejam ligados, são distintos, devendo permanecem em constante diálogo.

No estado liberal implantado no Brasil, historicamente a racionalidade econômica foi o que conferiu a tônica das ações do Estado e da sociedade em torno de interesses capitalistas que conformaram a compreensão socioeconômica e normativa. Essa racionalidade econômica capitalista orienta as características da instrumentalidade, da formalidade e da pacificação as quais têm determinado a atuação estatal. Nas palavras de Ramos Filho ${ }^{10}$, a característica da instrumentalidade racional visa normatizar a sociedade por meio de condicionamentos que impõem consequências econômicas a cada ação social. A característica da formalidade da racionalidade econômica se afiança no mito da igualdade entre contratantes e também a declaração de garantias e certezas jurídicas, prescritas com a única finalidade de garantir a reprodução do sistema econômico, garantindo as condições de funcionamento do Estado.

A característica da formalidade promove ainda a pacificação das relações sociais, "não pelo convencimento, mas pelo Poder de Império, sendo, portanto, um direito essencialmente repressivo ${ }^{11 " .}$ A racionalidade econômica reforça a mentalidade de que não há possibilidade de se reparar os inúmeros desafios sociais, a não ser mediante soluções matematicamente definidas e preocupadas apenas com questões financeiro-orçamentárias.

8 WEBER, Max. A ética protestante e o espírito do capitalismo. Tradução de M. Irene Szmrecsányi e Tamás Szmrecsányi. São Paulo: Pioneira Thomson Learning, 2005.

WEBER, Max. A ética protestante e o espírito do capitalismo, p. 46.

RAMOS FILHO, Wilson. Direito capitalista do trabalho: história, mitos e perspectivas. São Paulo: LTr, 2012, p. 50.

RAMOS FILHO, Wilson. Direito capitalista do trabalho: história, mitos e perspectivas, p. 50. 
Leff12, ao tratar das estruturas hodiernas da racionalidade econômica, assere que o mundo objetificado e coisificado pela racionalidade científica e economicista "desencadeia uma reação do risco e aniquila de antemão toda utopia como construção social de um futuro sustentável". A reflexão social pautada na racionalidade econômica reduz a força do trabalho, os valores culturais, as potencialidades do homem e sua capacidade inventiva em mercadorias dispostas pelo capital.

Os efeitos das regras e dos princípios dispostos a partir das opções do Constituinte são, simplesmente, correlacionados aos valores monetários que se pretendem colocar em circulação. As normas funcionam apenas como sistemas de incentivos para os seus destinatários segundo cálculos racionais dos sujeitos Ihes assegurando um preço ${ }^{13}$.

Ocorre que, consoante as reflexões de Habermas ${ }^{14}$, com frequência, o direito confere aparência de legitimidade ao poder ilegítimo. À primeira vista, ele não denota se as realizações de integração jurídica estão apoiadas no assentimento dos cidadãos ou se resultam de mera autoprogramação do Estado e do poder estrutural da sociedade ou, mais precisamente, do mercado.

A racionalidade marcadamente econômica impossibilita a legitimidade plena de direitos ditos universais, elencados no rol constitucional, especialmente, dos direitos sociais que demandam atuação estatal organicamente direcionada para a solidariedade (incompatível com a racionalidade econômica). É imperioso que as ações do Estado, o legítimo condutor da realização dos objetivos sociais, sejam conforme a materialidade axiológica constitucional, estabelecendo um parâmetro de coerência nas ações que sejam voltadas, efetivamente, realmente à promoção da existência digna. A modernidade liberal impele à fluidez de todos os aspectos, arrefecendo os mecanismos de segurança social que tencionam um parâmetro de manutenção de uma ordem social comprometida com a dignidade humana.

Como bem observa Ramos Filho ${ }^{15}$, a concepção potencializada pelos ideólogos do neoliberalismo, de que o capitalismo é o centro da cultura e da ideologia, acaba por determinar a condução da vida das pessoas. Essa concepção economicista acabou por estabelecer uma ligação umbilical entre neoliberalismo e globalização, de tal sorte que ambos os conceitos se confundiam definitivamente.

\footnotetext{
12 LEFF, Enrique. Racionalidade ambiental: a reapropriação social da natureza. Tradução de Luís Carlos Cabral. Rio de Janeiro: Civilização Brasileira, 2006, p. 127.

13 RAVINA, Carlos Morales De Setién. Las bases del análisis económico del derecho. In: KELMAN, Mark G.; LANDES, William M.; POSNER, Richard A. (Org.) Análisis Económico del Derecho. Bogotá: Siglo del Hombre / Universidad de los Andes/Pontificia Universidad JaverianaInstituto Pensar, 2011.

14 HABERMAS, Jürgen. Direito e democracia: entre facticidade e validade. vol. 1, p. 62.

15 RAMOS FILHO, Wilson. Direito capitalista do trabalho: história, mitos e perspectivas, p. 289.
} 
Esse aspecto perverso da globalização, ligado ao neoliberalismo autofágico, conforme observa Santos, é apenas uma das formas de globalização, sem dúvidas, a forma dominante e hegemônica, que:

[...] corresponde a um novo regime de acumulação do capital, um regime mais intensamente globalizado que os anteriores, que visa, por um lado, dessocializar o capital, libertando-o dos vínculos sociais e políticos que no passado garantiram alguma distribuição social e, por outro lado, submeter a sociedade no seu todo à lei do valor, no pressuposto de que toda a atividade social é mais bem organizada quando organizada sob a forma de mercado. A consequência principal desta dupla transformação é a distribuição extremamente desigual dos custos e das oportunidades produzidos pela globalização neoliberal no interior do sistema mundial, residindo aí a razão do aumento exponencial das desigualdades sociais entre países ricos e países pobres e entre ricos e pobres no interior do mesmo país ${ }^{16}$.

A globalização neoliberal representa, no modo em que é conduzida atualmente, retrocesso aos direitos humanos. O que impera é a simples defesa dos direitos de liberdade, com a intervenção mínima do Estado. Não é despendida, nesta perspectiva, relevância aos direitos socioeconômicos (de solidariedade), por isso são aprofundadas ainda mais as discrepâncias sociais. São exatamente nesse sentido as preocupações de Streck $^{17}$ com o constitucionalismo brasileiro:

[...] não se pode olvidar que, junto com a globalização, vêm os ventos neoliberais, assentados em desregulamentações, desconstitucionalizações e reflexividades. E tais desregulamentações - e suas derivações - colocam-se exatamente no contraponto dos direitos sociais-fundamentais previstos na Constituição brasileira.

É evidente, então, que a vertente flexibilizatória e precarizante atenta contra a predominância de uma racionalidade solidária (oposta à racionalidade econômica) que anseia a concretização dos valores definidos no núcleo constitucional.

\section{REESTRUTURAÇÃO DA RACIONALIDADE CONSTITUCIONAL COMO MECANISMO DE CONFORMAÇÃO SOLIDÁRIA E DEMOCRÁTICA DO PODER}

A racionalidade econômica neoliberal objetiva transformar os direitos sociais em mero arranjo formalista que visa à negociação econômica em torno das condições de trabalho pelos atores sociais, é o que aconteceu, por exemplo, com a Reforma Trabalhista (Lei nº 13.467 de 2017). Para a racionalidade econômica, o valor social do trabalho ou até mesmo a assistência social são meros mecanismos de condução da vontade social e de opressão e menosprezo à condição do trabalhador pobre. As ações sociais servem como instrumento para a redução da capacidade crítica e da consciência dos sujeitos sociais, de modo apenas a subjugar e tornar a camada de explorados mais

\footnotetext{
16 SANTOS, Boaventura de Sousa. Produzir para viver: os caminhos da produção não capitalista. Rio de Janeiro: Civilização Brasileira, 2002, p. 14.

17 STRECK, Lênio Luiz. Jurisdição Constitucional e Hermenêutica: perspectivas e possibilidades de concretização dos direitos fundamentaissociais no Brasil. Novos Estudos Jurídicos. Ano 8. n. 2, Itajaí: Univali, p. 257-302, maio/ago. 2003 , p. 278.
} 


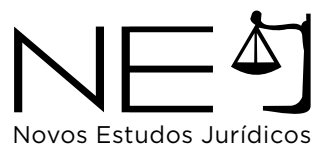

dócil. A simples realização de programas e ações da assistência social, a partir da vertente econômica, não leva à desconstrução da racionalidade economicista. A marginalização se perpetua, tornando esses sujeitos sociais estigmatizados e cada vez mais excluídos. No contexto capitalista, o direito do trabalho e a assistência social são considerados um custo e uma condição do processo econômico, cuja sustentabilidade depende das possibilidades de valorização do capital e do mercado.

É inegável que os direitos possuem um custo intrínseco. Muito embora, reconhecidamente, os direitos civis e políticos possuam um custo para o seu exercício, os direitos sociais demandam do Estado um alto grau de investimento e de dedicação para garantir o seu exercício pelos sujeitos mais vulneráveis economicamente, nas palavras de Nabais ${ }^{18}$, "[...] os custos dos direitos sociais concretizamse em despesas públicas com imediata expressão na esfera de cada um dos seus titulares, uma esfera que assim se amplia na exacta medida dessas despesas". A realização dos direitos sociais, como é o caso da assistência social, por exemplo, demanda um custo orçamentário cujo suporte financeiro é feito pelo pagamento dos impostos, o que categoriza o denominado "estado fiscal". Evidentemente, num contexto capitalista de ideologia neoliberal, em que a redução de custos para a maximização dos lucros é a diretriz do mercado, os custos com os serviços sociais são vistos como um alto preço que impede o crescimento econômico. Todavia, para além do crescimento econômico, a proposta constitucional brasileira é de desenvolvimento e de solidariedade.

Desse modo, para que se possa adequar à ambígua realidade ideológica brasileira, de uma economia de mercado, que tem por fim assegurar a todos existência digna, conforme os ditames da justiça social, é necessário que haja uma "consideração adequada dos deveres fundamentais e dos custos dos direitos ${ }^{19 "}$ em face da imperiosa necessidade de conferir eficácia a esses direitos.

Outrossim, a atuação estatal, mesmo na seara laboral, encontra respaldo na faceta econômica delineada pelo mercado, as quais se circunscrevem numa função marcadamente de proteção ao capital, potencializando suas funções macroeconômicas e a regulação das relações sociais. Essa compreensão econômica, no entanto, não pode prevalecer ante a materialidade axiológica definida pela Constituição, que tem a questão social como norte das preocupações sociais que devem ser enfrentadas pelos agentes públicos.

O trabalho e todos os valores a ele relacionados são vistos de modo secundário em relação à especulação financeira e ao afã predatório do capital transnacional, que amparado no princípio liberal (de que tudo o que não for proibido é permitido), atua mundialmente alterando e impedido qualquer política de redistribuição social da renda.

\footnotetext{
18 NABAIS, José Casalta. A face oculta dos direitos fundamentais: Os deveres e os custos dos direitos. Revista da AGU, Brasília, v.1, 2001. Disponível em: <http://www.buscalegis.ufsc.br/ revistas/index.php/buscalegis/article/view/15184/14748>. Acesso em: 10 jan. 2016, p. 12. 
Fica claro, então, que os direitos laborais, conquanto, indiscutivelmente, garantam um patamar mínimo civilizatório assegurando aos cidadãos condições mais dignas de vida, fazem-no num contexto ideológico em que a maximização dos lucros é o que importa. Tal ocorre com a sinalização e a autorização da História: sabe-se que a gênese do direito do trabalho encontra-se, em boa parte, sedimentada como instrumento de viabilização do capitalismo, garantindo-lhe meios para administrar conflitos sociais.

A dignidade humana serve então de contraponto normativo à racionalidade economicista que impera. A valorização humana, como pressuposto da dignidade que se pretende promover é, expressamente, abrigada na ordem constitucional brasileira. O valor dignidade, eleito e normatizado pela sociedade como cerne da ordem jurídica, serve de axioma para toda a ordem econômica e social. É nesse sentido que a Constituição Federal de 1988 afirma que a Ordem Econômica deve promover a existência digna (artigo 170) e que a Ordem Social é fundada no primado do trabalho (artigo193).

O que se coloca, a partir de 1988 com a Constituição Federal brasileira, são posturas estatais que, direcionadas para um fim específico (aqueles firmados no artigo $3^{\circ}$ ), devem nortear e dar diretrizes e fundamentos para a atuação do Poder Público em todas as esferas. Nessa esteira, Morand-Deviller ${ }^{20}$ revela que a reflexão atual acerca da organização do Estado não pode deixar de considerar os fenômenos econômicos (mundialização, globalização), nem muito menos os problemas daí advindos, como a ampliação das desigualdades regionais; recrudescimento dos quadros de pobreza e miséria; e exclusão intelectual, cultural e tecnológica.

Há que ser conduzida uma transformação social, indispensável à continuidade e à concretização das teorias democráticas, cujo fundamento maior é a união das regras do Estado Democrático de Direito, no afã de se efetivar a justiça social. À efetivação dos desejos de justiça social, portanto, se faz necessário que sejam afastados os inúmeros problemas que afligem a sociedade brasileira, especialmente aqueles construídos e aprofundados com a globalização.

Isto porque é a globalização que põe lente de aumento nos problemas sociais enfrentados pelos cidadãos brasileiros. Nas palavras de Bonavides ${ }^{21}$, a globalização é a nuvem negra sobre o Estado, a única ideologia da globalização econômica é a ausência de ideologias, cujo altar é a bolsa de valores, a única divindade é o lucro, e é formada em torno de uma única aliança, qual seja, o pacto neoliberal.

20 MORAND-DEVILLER, Jacqueline. O indivíduo e o corpo social: corpo biológico e corpo social p. 35-42. In: MARQUES, Claudia Lima; MEDAUAR, Odete; SILVA, Solange Teles da (Org.). O novo direito administrativo, ambiental e urbanístico: estudos em homenagem à Jacqueline Morand-Deviller. São Paulo: Revista dos Tribunais, 2010, p. 38.

21 BONAVIDES, Paulo. Os direitos humanos e a democracia. In: SILVA, Reinaldo Pereira (Org.). Direitos humanos como educação para justiça, p. 5-24. São Paulo: LTr, 1998, p. 22. 
É nesse sentido que Giddens ${ }^{22}$ assevera que as

[...] pressões pela democratização - que sempre enfrentam influências contrárias - são criadas pelos processos gêmeos de globalização e reflexividade institucional. [Assim] a globalização, a reflexividade e a destradicionalização criam espaços dialógicos que precisam, de alguma forma, serem preenchidos. Pode haver um engajamento dialógico com esses espaços... mas eles também podem ser ocupados por fundamentalismos.

As contradições propostas pela globalização são acentuadas pela hegemonia neoliberal, em que são postos em embate: a democracia política e social, os direitos de liberdade e os direitos sociais. A possibilidade de solução para a onda precarizante, que põe os direitos sociais em xeque, é a revitalização do trabalho como instrumento de reivindicações, inclusive com a ampliação do seu leque de proteção para a classe trabalhadora, que tem condições de viver do trabalho, mas que não encontra postos de trabalho suficientes para se inserir no mercado.

Todos esses dilemas sociais estão submetidos ao mesmo paradigma normativo e político que é a Constituição da República Federativa do Brasil de 1988, e ao modelo de Estado por ela construído. $O$ modelo normativo delineado pela sociedade brasileira se coloca como norte a orientar as estruturas políticas e sociais do Estado, definindo a atuação social a partir dos valores previamente definidos pela sociedade. E assim é o compromisso político firmado nas constituições contemporâneas.

Não por acaso, Masi' ${ }^{23}$, ao refletir sobre uma nova compreensão acerca do contrato social, afirma que a cláusula fundamental, a partir da qual se mantém a integridade do Estado, é o compromisso comum que une cada cidadão. Assim, afirma que "[...] cada um dê a todos os outros aquilo de que necessitem e, por sua vez, receba de todos os outros aquilo de que necessite" é parte do compromisso que mantém a coesão do Estado.

Essa possibilidade de construir uma sociabilidade pautada no compromisso comum, que se expressa por meio da solidariedade, apenas pode ser possível quando se coloca como centro das soluções políticas o trabalho. O trabalho é a base para as ações políticas e sociais, especialmente num contexto capitalista, no qual a solidariedade deva conduzir a racionalidade das decisões estatais.

Todavia, como já se afirmou no tópico anterior, embora se reconheça o trabalho como elemento central da sociedade brasileira, sua dignidade é ofuscada por uma racionalidade economicista e conflituosa imperante. A racionalidade econômica é fruto da complexa ampliação de influência do capital, sendo a principal fonte da ebulição dos conflitos entre capital e trabalho. 
Os que têm a capacidade de trabalhar são privados de ter acesso aos objetos produzidos pela lógica capitalista de produção. A racionalidade econômica aprisiona os homens e os reduz a meros objetos da produção, impedindo-os de se emancipar. A cidadania é estabelecida apenas como o reconhecimento de sujeitos, membros do Estado-Nação, na condição de subalternos e hierarquicamente inferiores.

Morais $^{24}$, atento ao contexto de crise social e econômica do Estado, reconhece a importância do papel da Constituição como parâmetro normativo da atuação Estatal nos seguintes termos:

Interpretar evolutivamente a Constituição é adequar o sentido da norma à realidade do tempo presente, ajustá-la ao seu "ambiente normativo" (onde o contexto da necessidade financeira assume uma importância central) e descobrir a sua relação objetiva de significado, tomando como base o seu programa interpretativo (o qual resulta de uma dialética entre texto, elemento lógico-sistemático, elemento histórico e elemento finalístico).

Embora o autor tenha razão quando admite a relação da interpretação constitucional com o panorama social, econômico e político, não se pode aceitar que a Constituição tenha seus limites definidos apenas pelas finalidades econômicas, na qual o sentido da norma deva ser adequado ao ambiente normativo centrado nas necessidades financeiras (de grande, mas não de exclusiva importância, no contexto constitucional hodierno).

Em tese, a constituição social brasileira, com viés dirigente, acaba por amarrar a política econômica, substituindo o processo de decisão política pelas imposições sociais presentes no próprio texto constitucional. Todavia, nas palavras de Bercovici e Massoneto25, é "Curioso é que os críticos entendem que são apenas os dispositivos constitucionais relativos a políticas públicas e direitos sociais que 'engessam' a política, retirando a liberdade de atuação do legislador".

Ao contrário, sob outra perspectiva, Hall e Taylor ${ }^{26}$ refletem, também reconhecendo a importância do papel do Estado no contexto de crise, que os componentes instrumentais da racionalidade econômica têm contribuído, em larga medida, para trazer à lume aspectos fundamentais da vida política que não podem ser subestimados, sob pena de agudizar e ampliar ainda mais as mazelas já existentes muito antes de um contexto de depressão econômica.

24 MORAIS, Carlos Blanco de. Curso de Direito Constitucional: Teoria da Constituição em tempo de crise. Tomo II, v. 2, Coimbra: Coimbra, 2014.

25 BERCOVICI, G.; MASSONETO, F. A constituição dirigente invertida: a blindagem da Constituição financeira e a agonia da constituição econômica, p. 57-77. Boletim de Ciências Econômicas, Lisboa, XLIX, 2006. p. 72.

26 HALL, Peter A. e TAYLOR Rosemary C. R. As três versões do neo-institucionalismo. Lua Nova, no. 58, pp. 193-223, 2003. 
A racionalidade econômica não pode ser simplesmente pautada em elementos que conduzam à ideia do mercado como motor propulsor das decisões institucionais que são, principalmente no caso do Brasil, um fator de relevância social imenso, haja vista as inúmeras mazelas históricas que afligem os milhares de pobres e miseráveis.

É evidente que os compromissos sociais, firmados normativamente a partir dos objetivos constitucionais, no sentido de implantar ações sociais, contêm um acordo social que tende a equilibrar interesses conflitantes. Esses acordos sociais, idealizados no contexto capitalista, são assentados sobre uma base racional que se apoia em uma ideologia que lança mão de interesses e orientações valorativas configuradas constitucionalmente e que, tendenciosamente, são interpretadas apenas consoantes os interesses do mercado.

\section{RACIONALIDADE SOLIDÁRIA: VALOR CONSTITUCIONAL E MATRIZ IDEOLÓGICA PARA SUPERAÇÃO DOS PARADIGMAS ECONÔMICOS}

A atuação prática dos reais detentores do poder limita a acepção da solidariedade, a mera expressão programática, destituída de força normativa. Reduzida ao jogo político-normativo das regras que põe em evidência apenas os valores econômicos da lucratividade e da competitividade, a solidariedade, obviamente, não é entendida pelos detentores do capital como valor social idealizado no sentido de beneficiar a todos.

A materialidade axiológica definida na Constituição é sim de tez solidária, mas é simplesmente ignorada. E não se pode simplesmente ignorar que, a partir da Constituição Federal brasileira de 1988, a solidariedade passa a compor de modo claro a matriz ideológico-política, normativa e econômica do Estado brasileiro, determinando os parâmetros para a realização da justiça em suas mais variadas facetas.

As diretrizes constitucionais da solidariedade estão presentes em vários momentos do texto da Constituição (como objetivo fundamental da República, no artigo 30 , I e III; nas diretrizes da política externa, no artigo 4, IX; como ditame de justiça social, expresso na Ordem Econômica, no artigo 170; e, como princípio expresso da Ordem Social, no artigo 193) e essa ampla previsão da solidariedade como fundamento normativo da sociedade brasileira não pode ser negligenciada.

A orientação solidária da Constituição deve servir à superação da racionalidade economicista, em prol de um paradigma solidário amplo, o qual enfeixe as compreensões (1) altruísta, (2) inclusiva e que promova a (3) hospitalidade. 
Na compreensão altruísta, a solidariedade é expressa como um elemento de orientação e edificação das ações sociais não como algo contemplativo, mas politicamente destinada à promoção de uma alteração social decorrente da ação coletiva, a partir da incorporação dos valores sociais.

Na expressão de Carducci27, decorre da expressão solidária do direito "[...] a urgência de um Direito Constitucional 'altruísta' como novo nomos da Terra, capaz de contestar o princípio da soberania e os interesses da razão de Estado como fundamento exclusivo da legitimidade política e da liberdade". Ainda, a expressão da liberdade decorre de uma "responsabilidade-para-com-o-outro"28", apresentandose como uma medida de autodeterminação que coaduna a expressão de cidadania solidária, na qual todos os cidadãos são responsáveis pelo exercício da cidadania uns dos outros.

Correlata a essa compreensão, Amartya $\operatorname{Sen}^{29}$ sustenta que "[...] a economia pode tornar-se mais esclarecedora se prestar uma atenção maior e mais explicita às considerações éticas que moldam o comportamento e o juízo humanos". A compreensão altruísta do direito revela uma alternativa para a superação do parâmetro economicista, promotor de crises e de exploração, ao tempo em que determina a ampliação da ideia de acesso aos bens fundamentais, ampliando a responsabilidade pela realização da cidadania para além da atuação estatal, mas também de todos os sujeitos sociais.

A ideia de uma sociedade aberta e plural, portanto altruísta, defendida por Carducci ${ }^{30}$, é reforçada por uma ideia de fraternidade ou irmandade, na qual haja a quebra da mentalidade economicista e egoísta. A superação da mentalidade economicista e egoísta, por meio de uma compreensão altruísta do outro, favorece o engajamento e o comprometimento social capaz de direcionar os sujeitos à realização da emancipação social, por meio da participação ativa nas lutas sociais.

A participação social é, por sua vez, capaz de promover melhorias e promoção da participação no usufruto dos benefícios do desenvolvimento, não apenas numa perspectiva individual, mas principalmente em face e em função do outro. A participação social representa desse modo uma expressão do compromisso e do comprometimento sociais que reflete no processo hermenêutico, o reconhecimento do outro:

[...] não simplesmente como destinatário de normas e interpretações, mas sim como sujeito ativo desta mesma comunhão constitucional, como ator do desenvolvimento das teorias constitucionais e dos métodos de compreensão dos problemas da igualdade complexa, da equidade, da ponderação, do julgar $[. . .]^{31}$.

CARDUCCI, Michele. Por um Direito Constitucional Altruísta. Porto Alegre: Livraria do Advogado, 2003, p. 59.

CARDUCCI, Michele. Por um Direito Constitucional Altruísta, p. 12.

SEN, Amartya K. Comportamento econômico e sentimentos morais. Lua Nova, 25, p. 103-130, 1992, p. 110.

CARDUCCI, Michele. Por um Direito Constitucional Altruísta, p. 18-20

CARDUCCI, Michele. Por um Direito Constitucional Altruísta, p. 71 
O ideário racional solidário deve permear, pois, a atuação Estatal nas esferas do Poder Executivo, do Legislativo e do Judiciário, tornando-se especialmente relevante nas duas últimas, por serem as responsáveis por disseminarem, na letra da lei e na sua aplicação judicial, o ideário altruísta, capaz de conferir ao direito de solidariedade a sua máxima efetividade. É o que se denomina "constitucionalismo altruísta" e participativo, o qual possibilita a inserção institucional do ideário racional solidário, o qual permite que as ações estatais sejam implementadas em função dos interesses coletivos e em favor da emancipação social.

A materialidade axiológica constitucional, assentada na solidariedade, favorece também uma compreensão inclusiva, expressa como um elemento de construção social. Para Habermas ${ }^{32}$, o sentido de inclusão está ligado à autonomia que integra todos os cidadãos por igual, significando que "[...] uma tal ordem política se mantém aberta à emancipação dos discriminados e à integração dos marginalizados sem os encerrar na uniformidade de uma comunidade popular homogênea (grifos do autor)". Assim, das palavras de Habermas, é possível se depreender que a inclusão é expressa pelo reforço à ideia altruísta e solidária como decorrente da necessidade de busca de uma participação qualificada de todos os sujeitos no processo de condução da vida social. A realização dos processos sociais depende da interferência de todos os cidadãos e que, portanto, serão usufrutuários dos efeitos do processo político-social-econômico do desenvolvimento. Essa cosmovisão da necessidade de interferência mútua no processo de desenvolvimento expressa a vertente democrática e solidária da concretização do poder político, que representa a vontade do povo (e não dos poderes econômicos que controlam o poder).

Nas palavras de Habermas ${ }^{33}$, as "[...] leis satisfazem a condição de uma universalidade entendida de modo programático, e de modo nenhum apenas semântico, se forem geradas num processo inclusivo de representação popular caracterizado pela discussão e pela publicidade". Dessa forma, a acepção de luta social acaba por ser reforçada e reflete de modo mais preciso a ideia de legitimidade da inclusão como elemento da solidariedade.

A legitimidade do Estado, portanto, muito mais do que à ideia de igualdade, está ligada à garantia de um processo inclusivo de formação de consciência política (associando a ideia de opinião e de vontade), na qual a solidariedade impõe uma "inclusividade" dos sujeitos nos rumos das ações sociais. Essa expressão ultrapassa os próprios limites territoriais do Estado-Nação, ampliando-se para uma compreensão global, plural, em face da organização mundial, no sentido da extensão universal dos direitos humanos. 
Obviamente, essa extensão universalista dos direitos humanos não pode agredir a voluntariedade, devendo respeitar a independência externa da existência dos povos e a autodeterminação nacional. Assim, em um primeiro momento, deve haver a inclusão dos sujeitos sociais à condição de cidadania, abrindo-se, então, para o Estado a ideia de fonte de legitimação, juridicamente mediada, em favor dos valores encerrados naquela comunidade ${ }^{34}$. A compreensão inclusiva, na proposta habermasiana, estabelece, a partir da alteridade, a centralização dos processos sociais na intersubjetivização ou na interação social, na qual todos os cidadãos se reconhecem como livres e iguais ${ }^{35}$. Essa alteridade, para além da compreensão interna de altruísmo e solidariedade, esforça-se para uma apreensão das diferenças a partir do filtro da sensibilidade ${ }^{36}$. Partindo dessa constatação, a formação pública da opinião e da vontade, no relacionamento intersubjetivo dos cidadãos, ocorre segundo os discursos e, especialmente, os valores que visam à aceitabilidade racional das normas à luz dos interesses e das necessidades gerais.

Os interesses e as necessidades gerais, expressos por Habermas, funcionam como orientações compartilhadas e princípios fundamentais da sociedade ${ }^{37}$, determinando uma apreensão mais ampla da própria solidariedade. É nesse sentido que Gonçalves ${ }^{38}$ observa que as graves ameaças a uma uniformização forçada dos interesses são determinadas, especialmente, pela confusão entre a religiosidade e o espaço público, que não promove inclusão, mas intolerância e segregação.

É o que se constata ainda nas reflexões de Gonçalves e Mascarenhas ${ }^{39}$, para quem:

Não cabe em uma sociedade heterogênea, como é a existente na modernidade, uma unificação e aproximação entre elementos diversos. Sob o argumento de unificar, o que ocorrerá é a desagregação daqueles que não estão alinhados ao pensamento "majoritário". O que se deve buscar é uma sociedade e ordenamento hiperinclusivo, para que se atendam às demandas dos mais distintos setores sociais.

Deve-se então aduzir que o reconhecimento do outro, como uma expressão da isonomia e da sociabilidade humana, decorre da cooperação entre os cidadãos, fundada na justiça, na reciprocidade e na inclusão como expressão da solidariedade. Sob esse enfoque é adequado afirmar, nas palavras de Machado ${ }^{40}$, que:

34 HABERMAS, Jürgen. A inclusão do outro: estudos de teoria política. Tradução de George Sperber, Paulo Astor Soethe e Milton Camargo Mota. 2. ed. São Paulo: Edições Loyola, 2004, p. 157.

35 HABERMAS, Jürgen. A inclusão do outro: estudos de teoria política, p. 160.

36 HABERMAS, Jürgen. A inclusão do outro: estudos de teoria política, p. 172.

37 HABERMAS, Jürgen. A inclusão do outro: estudos de teoria política, p. 164.

38 GONÇALVES, Rogério Magnus Varela. O papel da advocacia no aprimoramento da democracia participativa: o caso da efetivação das políticas públicas. In: MIGUEL, Francisca et al. (Org.). Conferência Nacional dos Advogados, Anais da XXII Conferência Nacional dos Advogados: constituição democrática e efetivação dos direitos, Rio de Janeiro, 20 a 23 de outubro de 2014. Brasília: OAB, Conselho Federal, 2015, p. 190.

39 GONÇALVES, Rogério Magnus Varela; MASCARENHAS, Igor de Lucena. Análise acerca da compatibilidade da existência de feriados religiosos em um Estado laico. Direito e Desenvolvimento, v. 4, p. 187-2012, 2013, p. 11.

40 MACHADO, Jónatas Eduardo Mendes. Liberdade religiosa numa comunidade constitucional inclusiva: dos direitos da verdade aos direitos dos cidadãos. Boletim da Faculdade de Direito da Universidade de Coimbra, 1996, p. 287. 
Uns e outros sabem que podem prosseguir livremente as suas distintas visões do mundo e da vida (do bem e da verdade) com a certeza de que não serão, por esse facto, objecto de um tratamento jurídico diferenciado, nem afectados no seu sentimento de igual dignidade como membros de pleno direito da comunidade política.

A ideia de inclusão social passa então a estar cada vez mais próxima à feição da emancipação social, na qual os sentimentos de pertencimento à comunidade permitem e colaboram para uma participação cada vez mais tolerante, diversa, ativa e igualitária dos sujeitos sociais.

Para melhor evidenciar, a construção de uma sociedade mais livre, justa, solidária e democrática determina uma intervenção na realidade de modo a aproximar cada vez mais o texto constitucional (em especial, a previsão dos direitos fundamentais) do ideário democrático e inclusivo, capaz de determinar a promoção das condições básicas de vida para todos ${ }^{41}$. O que é expresso também por Machado ${ }^{42}$, ao afirmar que a expressão dos direitos fundamentais alicerça a "[...] igual consideração e respeito devida a todos os indivíduos".

Em um contexto de desigualdade material (social e econômica), o papel inclusivo do Estado, em face do texto Constitucional, passa a deter uma feição positiva, exigindo a adoção de medidas concretas de promoção da igualdade em seu sentido material. Essas medidas positivas possibilitam a real fruição das liberdades instrumentais aptas à promoção do desenvolvimento, numa clara acepção inclusiva, que apenas é possível com a concretização dos direitos sociais.

A concepção inclusiva dos direitos sociais, proposta pelo texto constitucional, passa a ser entendida como um elemento substancial e estruturalmente possibilitador da inclusão de todos os cidadãos e grupos de cidadãos com igual consideração e respeito ${ }^{43}$. Assim, a proposta inclusiva, pautada na sociabilidade intersubjetiva, não se encerra nela, mas reverbera, de modo claro na ideia de compreensão de justiça social, que a associa ao reconhecimento do outro.

O reconhecimento do outro, por sua vez, reforça a necessidade de realização da cidadania em sua feição solidária, a qual se liga, fundamentalmente, ao reconhecimento da imprescindibilidade da busca pela igualização dos sujeitos sociais, numa perspectiva de promoção do desenvolvimento, como fator inclusivo.

O desenvolvimento passa a constituir, então, direito e não apenas resultado econômico, ao qual se acostam as acepções da solidariedade, exigindo, pois, realização material da cidadania

41 SARMENTO, Daniel; SOUZA NETO, Cláudio Pereira de. Direito Constitucional: teoria história e método de trabalho. Belo Horizonte: Fórum, 2012, p. 18.

42 MACHADO, Jónatas Eduardo Mendes. Liberdade religiosa numa comunidade constitucional inclusiva: dos direitos da verdade aos direitos dos cidadãos, p. 290

43 GONÇALVES, Rogério Magnus Varela. O papel da advocacia no aprimoramento da democracia participativa: o caso da efetivação das políticas públicas, p. 212. 
solidária. O que abre ainda a possibilidade de reconhecer dentro da esfera da solidariedade outra acepção de hospitalidade.

A acepção da hospitalidade, como faceta da solidariedade, é relacionada à promoção da tolerância e do acolhimento. Derrida ${ }^{44}$ estabelece o conteúdo da ética nos termos da hospitalidade, uma vez que "[...] não existe vínculo social sem um princípio de hospitalidade", o qual é definido como conteúdo da própria ética.

A necessidade de convivência social compreende uma ideia cosmopolita do direito, a qual se agrega à perspectiva kantiana de moral. Para Kant ${ }^{45}$, a ideia cosmopolita do direito é representada por um "dever" que liga os sujeitos uns aos outros ${ }^{46}$. Dever esse que intensifica e fortalece a ideia de ética e de valores morais.

Fica clara, pois, a ligação da visão cosmopolita kantiana com a acepção de hospitalidade. Ambas promovem uma intensificação dos valores morais, os quais, nas palavras de Pureza ${ }^{47}$, sugerem a superação dos "[...] riscos de egoísmo e de solidão que atravessam a incidência individual dos direitos [...]", cuja realização é impossível "[...] fora de um quadro de conjugação dos esforços de todos os actores do jogo social: indivíduos, Estado, entidades públicas e privadas, comunidade internacional".

Nessa medida, a noção espacial ou territorial que limita o acesso aos bens sociais perde importância. O acolhimento ao outro perpassa 0 "[...] lugar da residência familiar tanto quanto ao modo de estar aí e de se relacionar consigo e com os outros, com os outros como os seus ou como estrangeiros ${ }^{48 "}$. Assim, a hospitalidade, muito mais do que uma mera acepção da solidariedade, é a expressão de um dever de solidariedade para com todos, independentemente de procedência.

Associada a perspectiva de acolhimento, a tolerância reverbera também na compreensão da hospitalidade, uma vez que a necessidade de convivência social, altruísta e humanista, não é possível sem que o respeito e a diversidade sejam tomados em consideração, como uma decorrência lógica da igualdade que vige e deve ser posta em prática.

A compreensão solidária da hospitalidade, nos termos da tolerância e do acolhimento, é, portanto, fundada nos princípios do respeito e da diversidade, que devem ser tomados em consideração, quando da realização de ações voltadas à emancipação social. Referida concepção

44 DERRIDA, Jacques. Papel máquina. São Paulo: Estação Liberdade, 2004, p. 249.

45 KANT, Immanuel. Para a paz perpétua. Tradução de Bárbara Kristensen. Rianxo: Instituto Galego de Estudos de Segurança Internacional e da Paz, 2006, p. 83.

$46 \quad$ KANT, Immanuel. Para a paz perpétua, p. 83.

47 PUREZA, José Manuel. O património comum da humanidade: rumo a um direito internacional. Col. Saber imaginar o social, 12, Porto: Afrontamento, 1998, p. 81-82.

48 NASCIMENTO, Evando. Introdução. In: NASCIMENTO, Evando; GLENADEL, Paula. Em torno de Jacques Derrida. Rio de Janeiro: 7Letras, 2000, p. 20. 
aproxima o ethos altruísta e inclusivo, correlato à hospitalidade, ampliando a compreensão acerca do outro. Como exemplo e como expressão do dever de solidariedade, é possível tratar da acepção da hospitalidade em discussões acerca dos benefícios da seguridade social, especialmente da assistência, quando se trava o embate acerca da possibilidade (ou não) de percepção, pelos imigrantes estrangeiros, dos benefícios de prestação continuada ou do Bolsa Família. As famílias refugiadas merecem e precisam que, como dever de hospitalidade, haja o reconhecimento da sua dignidade e a promoção do seu bem-estar.

Waldaman, Baraldi e Almeida ${ }^{49}$ pronunciam-se em favor da realização de uma solidariedade para além, inclusive, dos direitos de subsidiariedade ou reciprocidade internacional, no sentido de garantir o acesso universal e igualitário às ações e aos serviços da assistência social. A jurisprudência brasileira também tem sido favorável à possibilidade de concessão de benefícios assistenciais aos imigrantes, inclusive no âmbito do Supremo Tribunal Federal, que no Recurso Extraordinário $\mathrm{n}^{\circ}$. 587.970 reconheceu a repercussão geral da matéria.

Nas Ações Civis Públicas nº 0012072192013403999 e nº. 00002189220074036004 , ambas decididas no Tribunal Regional Federal da $3^{a}$ Região, foi confirmada a possibilidade de se conceder a estrangeiros residentes no Brasil o benefício assistencial do artigo 203 da Constituição Federal. Nessas decisões, verifica-se, de modo claro, a proeminência da acepção hospitalidade, cujo respaldo normativo é a materialidade axiológica constitucional do valor solidariedade.

Como se afirmou, a materialidade axiológica constitucional é centrada na previsão expressa do princípio-objetivo constitucional de "construção de uma sociedade livre, justa e solidária", o qual determina a promoção do bem-estar de todos "sem distinções de qualquer natureza". Desse modo, a solidariedade, assentada numa vertente hospitaleira (tolerante e acolhedora), possibilita a elevação do padrão de vida das pessoas mais carentes, promovendo a efetivação de um paradigma central da atuação estatal.

Logo, o fortalecimento da isonomia entre todos os sujeitos sociais, a partir de uma compreensão solidária de cidadania, está ligado diretamente aos resultados da adoção das medidas especiais como instrumento para proporcionar bem-estar. A ampla compreensão da solidariedade demonstra a intensificação dos valores morais que definem a sociedade, apresentando a possibilidade de uma adaptação da vivência social, bem como promovendo o surgimento de uma forma diferente de conceber as relações sociais (inclusive na perspectiva do direito internacional).

49 WALDAMAN, Tatiana Chang; BARALDI, Camila Bibina Freitas; ALMEIDA, Tali Pires de. O direito dos imigrantes ao benefício de prestação continuada: uma questão de cidadania. In: SERAU JUNIOR, Marco Aurélio; COSTA, José Ricardo Caetano. Benefício assistencial: temas polêmicos - Lei n. 8,742/93. São Paulo: LTr, 2015, p. 116-238. 
A efetivação dos valores sociais, por meio de medidas positivas do Estado e da sociedade, é capaz de gerar transformações a partir do compartilhamento equitativo de prerrogativas e, principalmente, de responsabilidades entre os cidadãos. Como se pode visualizar, a solidariedade é apresentada a partir do seguimento de regras, condições, leis e valores postos em face do outro, os quais tornam possível a apreensão altruísta, inclusiva e hospitaleira (com respeito, tolerância e acolhimento).

\section{CONSIDERAÇÕES FINAIS}

Na conformação do ordenamentojurídico à facticidade dos seus valores, devem ser estabelecidos mecanismos que promovam a sua eficácia. Deve ser estruturada uma forma de atuação estatal, na qual sejam superados os desafios relativos à concretização dos direitos dos mais pobres.

A cláusula social que determina a inserção da solidariedade como elemento vocacional das ações do Estado brasileiro revela a nova racionalidade que deve nortear essa atuação estatal. Assim, a discricionariedade da atuação estatal, fundada na solidariedade, funciona como mediadora no embate da ideologia neoliberal num Estado que se pretende social.

Deste modo, não se pode olvidar que devem ser permanentes as opções hermenêuticas assentadas na elevação dos valores sociais da constituição. A tentativa de interpretação assentada numa hermenêutica estática e positivista impede a confluência da estrutura principiológica que determina e confere a maleabilidade necessária para que se privilegie o ser humano, a partir da ideia de existência digna que colore e define a ordem econômica brasileira, delineada a partir de 1988.

O Estado Democrático Solidário de Direito, visto como um passo adiante em relação ao Estado Social, é um instrumento necessário à implantação das promessas não cumpridas pelo Estado Liberal. O Estado Democrático Solidário de Direito representa, assim, a vontade constitucional de realização dos valores sociais definidos pelo Estado Social. É nesse sentido que se acosta à definição de Streck ${ }^{50}$ como "plus normativo em relação ao direito promovedor-intervencionista próprio do Estado Social de Direito".

O primado da Constituição como legitimadora dos processos democráticos de implementação das políticas assistenciais fundamenta a inserção de princípios constitucionais que são responsáveis pela interferência positiva na adoção de meios cada vez mais capazes de emancipar o cidadão, o que exige um esforço altruísta, includente e hospitaleiro.

50 STRECK, Lênio Luiz. A hermenêutica e as possibilidades de superação do positivismo pelo (neo)constitucionalismo. In: ROCHA, Leone Severo; STRECK, Lenio Luiz (Org.). Constituição, sistemas sociais e hermenêutica. Porto Alegre: Livraria do Advogado, 2005 , p. 38. 
Os princípios e os valores do Estado Democrático reconhecidos na Constituição se juntam num planejamento arquitetônico construído a partir da organização social que serve, em última instância, ao próprio povo por meio da aplicação racional dos direitos sociais. A implementação administrativa de políticas sociais que desenvolve sua força na realização dos fins coletivos. É, ainda, nessa medida, que se estabelece a ideia de que as estruturas administrativas, legislativas e judiciais, ligadas à realização da atuação estatal, são o produto do intenso esforço de elaboração de estruturas cada vez mais eficazes, destinadas a cumprir as tarefas ligadas à realização dos objetivos racionalmente eleitos pelo Estado. O que, nos dias atuais, tem sido deixado de lado, sob o argumento redutor economicista.

É necessário que se afaste a compreensão da lógica de mercado - privatista e egoísta por natureza - para que possa emergir uma lógica de Estado, preocupada com o interesse público e com as finalidades sociais. A ação, dotada de sentido, permite ao homem construir sua história. Esse modelo individual configura-se também na sociedade, por meio do paradigma capitalista, uma vez que o homem se insere na sociedade de modo a se coadunar à racionalidade econômica prevalecente, já que as diretrizes normativas que regem o sistema jurídico acabam por se tornar a motivação das ações.

A digressão que condiciona a ação humana em direção a determinado sentido é o que condiciona a necessidade de superação do paradigma racional econômico por um novo paradigma assentado na solidariedade, capaz de promover desenvolvimento, dignidade e justiça social, valores tão caros ao constitucionalismo brasileiro.

\section{REFERÊNCIAS DAS FONTES CITADAS}

BERCOVICl, G.; MASSONETO, F. A constituição dirigente invertida: a blindagem da Constituição financeira e a agonia da constituição econômica. Boletim de Ciências Econômicas, Lisboa, XLIX, 2006. p. 57-77.

BOLAÑOS, Liliana Ortiz. Los derechos fundamentales como limites ao poder y la fuerza normativa da constituicion. In: Derecho y sociedad: Revissta del centro de investigaciones sociojurídicas, vol. 1, n. 1, Bogotá: Faculdades de Ciencias Jurídicas y del Estado, maio 2008, p. 13-42.

BONAVIDES, Paulo. Os direitos humanos e a democracia. In: SILVA, Reinaldo Pereira (Org.). Direitos humanos como educação para justiça. São Paulo: LTr, 1998, p. 5-24.

CARDUCCI, Michele. Por um Direito Constitucional Altruísta. Porto Alegre: Livraria do Advogado, 2003.

DEJOURS, Cristophie. A banalização da injustiça social. Rio de Janeiro: FGV, 1999

DERRIDA, Jacques. Papel máquina. São Paulo: Estação Liberdade, 2004.

FIANI, Ronaldo. Teoria dos jogos: para cursos de administração e economia. 2. ed. rev. e atual. Rio de Janeiro: Elsevier, 2006.

GIDDENS, Anthony. Para além da esquerda e da direita. São Paulo: UNESP, 1996. 
GONÇALVES, Rogério Magnus Varela. O papel da advocacia no aprimoramento da democracia participativa: o caso da efetivação das políticas públicas. In: MIGUEL, Francisca et al. (Org.). Conferência Nacional dos Advogados, Anais da XXII Conferência Nacional dos Advogados: constituição democrática e efetivação dos direitos, Rio de Janeiro, 20 a 23 de outubro de 2014. Brasília: OAB, Conselho Federal, 2015.

GONÇALVES, Rogério Magnus Varela; MASCARENHAS, Igor de Lucena . Análise acerca da compatibilidade da existência de feriados religiosos em um Estado laico. Direito e Desenvolvimento, v. 4, p. 187-2012, 2013.

HABERMAS, Jürgen. A inclusão do outro: estudos de teoria política. Trad. George Sperber, Paulo Astor Soethe e Milton Camargo Mota. 2. ed. São Paulo: Edições Loyola, 2004

HABERMAS, Jürgen. Direito e democracia: entre facticidade e validade. vol. 1. Trad. Flávio Beno Siebeneichler. Rio de Janeiro: Tempo Brasileiro, 1997.

HABERMAS, Jürgen. Teoria políticas: Obras escolhidas. v. 4. Lisboa: 70, 2015.

HALL, Peter A. e TAYLOR Rosemary C. R. As três versões do neo-institucionalismo. Lua Nova, no. 58, pp. 193-223, 2003.

KANT, Immanuel. Para a paz perpétua. Trad. Bárbara Kristensen. Rianxo: Instituto Galego de Estudos de Segurança Internacional e da Paz, 2006.

LEFF, Enrique. Racionalidade ambiental: a reapropriação social da natureza. Trad. Luís Carlos Cabral. Rio de Janeiro: Civilização Brasileira, 2006.

MACHADO, Jónatas Eduardo Mendes. Liberdade religiosa numa comunidade constitucional inclusiva: dos direitos da verdade aos direitos dos cidadãos. Boletim da Faculdade de Direito da Universidade de Coimbra, 1996.

MASI, Domenico de. Criatividade e grupos criativos. Trad. Léa Manzi e Yadyr Figueiredo. Rio de Janeiro: Sextante, 2003.

MORAIS, Carlos Blanco de. Curso de Direito Constitucional: Teoria da Constituição em tempo de crise. Tomo II, v. 2, Coimbra: Coimbra, 2014.

MORAND-DEVILLER, Jacqueline. O indivíduo e o corpo social: corpo biológico e corpo social. In: MARQUES, Claudia Lima; MEDAUAR, Odete; SILVA, Solange Teles da (Org.). O novo direito administrativo, ambiental e urbanístico: estudos em homenagem à Jacqueline Morand-Deviller. São Paulo: Revista dos Tribunais, 2010, p. 35-42.

NABAIS, José Casalta. A face oculta dos direitos fundamentais: Os deveres e os custos dos direitos. Revista da AGU, Brasília, v.1, 2001. Disponível em: <http://www.buscalegis.ufsc.br/revistas/index.php/buscalegis/article/view/15184/14748> Acesso em: 10 jan. 2016.

NASCIMENTO, Evando. Introdução. In: NASCIMENTO, Evando; GLENADEL, Paula. Em torno de Jacques Derrida. Rio de Janeiro: 7Letras, 2000.

PUREZA, José Manuel. 0 patrimônio comum da humanidade: rumo a um direito internacional. Col. Saber imaginar o social, 12, Porto: Afrontamento, 1998.

RAMOS FILHO, Wilson. Direito capitalista do trabalho: história, mitos e perspectivas. São Paulo: LTr, 2012.

RAVINA, Carlos Morales De Setién. Las bases del análisis económico del derecho. In: KELMAN, Mark G.; LANDES, William M.; POSNER, Richard A. (Org.). Análisis Económico del Derecho. Bogotá: Siglo del Hombre / Universidad de los Andes/ Pontificia Universidad Javeriana-Instituto Pensar, 2011.

RIPERT, Georges. A Regra Moral nas Obrigações Civis. Campinas: Bookseller, 2000.

SANTOS, Boaventura de Sousa. Produzir para viver: os caminhos da produção não capitalista. Rio de Janeiro: Civilização Brasileira, 2002.

SARMENTO, Daniel; SOUZA NETO, Cláudio Pereira de. Direito Constitucional: teoria história e método de trabalho. Belo Horizonte: Fórum, 2012. 
SEN, Amartya K. Comportamento econômico e sentimentos morais. Lua Nova, 25, p. 103-130, 1992.

SOARES JÚNIOR, Jair. A influência do argumento econômico sobre o jurídico na aplicação do direito à assistência social. In: SERAU, Marco Aurélio et al. (Org.). Benefício assistencial: Lei n 8.742/93 - temas polêmicos, p. 32-42. São Paulo: LTr, 2015.

STRECK, Lênio Luiz. A hermenêutica e as possibilidades de superação do positivismo pelo (neo)constitucionalismo. In: ROCHA, Leonel Severo; STRECK, Lenio Luiz (Org.). Constituição, sistemas sociais e hermenêutica. Porto Alegre: Livraria do Advogado, 2005.

STRECK, Lênio Luiz. Jurisdição Constitucional e Hermenêutica: perspectivas e possibilidades de concretização dos direitos fundamentais-sociais no Brasil. Novos Estudos Jurídicos. Ano 8. n. 2, Itajaí: Univali, p. 257-302, maio/ago. 2003.

WALDAMAN, Tatiana Chang; BARALDI, Camila Bibina Freitas; ALMEIDA, Tali Pires de. O direito dos imigrantes ao benefício de prestação continuada: uma questão de cidadania. In: SERAU JUNIOR, Marco Aurélio; COSTA, José Ricardo Caetano. Benefício assistencial: temas polêmicos - Lei n. 8,742/93. São Paulo: LTr, 2015, p. 116-238.

WEBER, Max. A ética protestante e o espírito do capitalismo. Tradução de M. Irene Szmrecsányi e Tamás Szmrecsányi. São Paulo: Pioneira Thomson Learning, 2005.

RECEBIDO EM: 27/04/2019

APROVADO EM: 10/02/2020 